\title{
Sistemas de Classificação Intuitiva como Possibilidade para o Ensino de Diversidade Animal no Contexto da Educação do Campo
}

\section{Intuitive Classification Systems as a Possibility for Teaching Animal Diversity in the Context of rural Education}

\author{
Diany Kelly Cardoso de Sousa ${ }^{\circledR}$ Brasil \\ Alessandra Alexandre Freixo ${ }^{(0)}$ Brasil
}

O presente artigo apresenta e avalia uma possibilidade para o ensino sobre diversidade animal a partir de uma investigação sobre as classificações intuitivas de estudantes de uma escola de ensino fundamental no contexto do campo. A pesquisa aconteceu em uma Escola Família Agrícola no Semiárido da Bahia, por meio de oficinas das quais participaram 44 estudantes das turmas de $7^{\circ}$ e $9^{\circ}$ anos do ensino fundamental, no ano de 2017. Pautada nos aspectos metodológicos da pesquisa-ação, os encontros ocorreram em três momentos distintos, nos quais realizou-se um levantamento dos conhecimentos etnobiológicos dos estudantes sobre a fauna, por meio de desenhos e descrições. Os estudantes realizaram classificações intuitivas com os animais citados e, por fim, abriuse espaço para um possível diálogo de saberes, estimulando os estudantes a perceber semelhanças ou diferenças entre os modos de agrupar os animais, sejam suas classificações intuitivas, seja a classificação filogenética. Os dados obtidos passaram por análise de conteúdo. Os resultados apontam que algumas das categorias utilizadas pelos estudantes para agrupar os animais, como "animais da caatinga", "animais nojentos", "animais de produção", expressam o valor simbólico e cultural que os estudantes apresentam sobre animais que pertencem ou não ao seu ambiente e convívio. A abordagem utilizada na presente pesquisa mostra grande potencial enquanto estratégia que permite a criação de um espaço em que os estudantes possam interagir e participar, promovendo o diálogo entre professor/aluno/conteúdo.

Palavras-chave: Diversidade animal; Etnobiologia; Escola Família Agrícola.

This paper aims to present and evaluate a tool for teaching animal diversity. In this experience, we sought to investigate the elementary students' intuitive classifications about animal diversity in the context of rural education. The activities were developed in a Family Farm School in the Semi-arid of Bahia, Brazil, through workshops in which forty-four students in the 7th and 9th grades participated in 2017. Based on the methodological aspects of action research, the meetings took place at three different 
times. First, we carried out a survey based on descriptions and drawings of the students' ethnobiological knowledge about fauna. Second, students performed intuitive classifications of the animals that they cited. Finally, the students were encouraged, through a dialogue of knowledge, to realize the similarities and differences between the ways of grouping animals, whether their intuitive classifications or the phylogenetic classification. The data obtained went through content analysis. The results show that some of the categories used by the students to group animals, such as "Caatinga animals", "disgusting animals", "production animals", express the symbolic and cultural value that students have about animals that belong or not to their environment and conviviality. We can also conclude that the approach used in this research shows great potential as a strategy that allows the creation of a space in which students can interact and participate, promoting the dialogue between teacher/student/content.

Keywords: Animal diversity; Ethnobiology; Family Farm School.

\section{Introdução}

A diversidade de vida que nos cerca é gritante e ao mesmo tempo intrigante, sendo praticamente impossível existir alheia às formas, cores, aos sons, tamanhos, cheiros, sabores, assim como tantas outras sensações que ela nos proporciona. Mesmo que alguns não tenham ideia da complexidade que a envolve, essa percepção, presente desde os primórdios da existência humana, tem sido motivo de incessantes perguntas. Uma vez que os seres humanos tomaram consciência da variedade de formas de vida existente, surgiu também a necessidade de organizá-la e classificá-la; esta capacidade parece ser constituinte da nossa essência. Para Waizbort (2000, p. 143), "colocar objetos em classes exige toda uma série de operações mentais que ninguém duvida que sejam exclusivos, de uma certa maneira, do homem", basta observar nossa rotina diária, constantemente estamos separando e organizando as coisas em grupos, fazemos isso em casa, na escola, no trabalho ou em qualquer outro lugar em que este modo de proceder seja necessário.

Se classificamos simples objetos em nosso cotidiano não seria então diferente ao tratarmos a abundante e quase que indescritível diversidade existente na natureza, por isso existem ramos específicos dentro das ciências biológicas que se ocupam em identificar e classificar os seres vivos. Para além dos métodos utilizados no meio científico para ordenar e estudar a biodiversidade, e das abordagens didáticas necessárias para tornar esse conhecimento acessível aos estudantes em sala, é preciso destacar que os seres humanos têm utilizado diferentes modos de classificação que expressam diferentes formas de entender e explicar o universo e os seres que nele vivem.

Este conjunto de conceitos culturalmente aprendidos que compõem a marca de determinados grupos pode ser definido como conhecimento tradicional, que mais especificamente significa "o saber e o saber fazer, a respeito do mundo natural e sobrenatural, gerados no âmbito da sociedade não urbano/industrial e transmitidos 
oralmente de geração em geração" (Diegues, 2000, p. 30).

Assim, o sujeito do campo, como outros grupos sociais, possui sua própria interpretação da natureza e de seus fenômenos. Portanto ao trabalhar com diversidade biológica nesse contexto, é imprescindível que a diversidade local seja o ponto de partida para o ensino desse tema. Corroborando esse pensamento, Freire (1992, p. 86), orienta que "a localidade dos educandos é o ponto de partida para o conhecimento que vão criando do mundo". Sendo assim, aspectos próprios da região devem ser respeitados e valorizados, como o tipo de solo, de clima, os animais, as plantas e todos os outros que caracterizam a vida da comunidade.

Diante do exposto, essa investigação teve como objetivo compreender como o uso de classificações intuitivas pode colaborar com o ensino sobre diversidade animal no contexto educacional do campo. Para alcançar este objetivo, foram desenvolvidas as seguintes estratégias metodológicas: realização de um levantamento do conhecimento etnozoológico dos estudantes, de modo a conhecer as estratégias de classificação biológica utilizadas por eles, e a proposição de oficinas de ciências sobre o tema da diversidade e classificação biológica na promoção do diálogo entre saberes e contextualização do ensino a respeito dos animais.

\section{Escola do Campo: Contexto, desafios e possibilidades}

Todo ser humano tem direito à educação e essa deve ser assegurada pelo Estado, de acordo com a constituição de 1988, artigo 205 (Constituição da República Federativa do Brasil de 1988). O que se percebe, no entanto, é que esse direito universal e intrínseco ao ser humano, o qual possibilita o conhecimento de todos os outros ainda não alcançou sua plena concretização, havendo um longo caminho a ser percorrido até que se alcance esse alvo. Muitos são os problemas relacionados à educação em nosso país, mas a situação se agrava ao considerarmos a educação no meio rural. Essa esteve por muito tempo em segundo plano no que tange às políticas educacionais voltadas à materialização desse direito social.

A despeito do descaso historicamente conhecido para com o Brasil campesino, sempre existiram agentes precursores de mudanças. A trajetória da educação do campo pode ser traçada a partir de marcos e conquistas que ao longo do tempo foram agregando força à luta pela real universalização do direito à educação. A educação do campo surge, então, em resposta à luta protagonizada pelos movimentos sociais no campo, como o Movimento dos Trabalhadores Rurais Sem-Terra (MST), e a mobilização de diversos outros sujeitos, que demandavam das instâncias governamentais não apenas uma política pública que atendesse às especificidades educacionais da população do campo, mas também que atendesse de forma holística as suas necessidades e assegurassem seus direitos enquanto cidadãos (Silva, M. S., 2006).

No atual cenário do campo brasileiro apresentam-se diversas experiências educacionais, entre as quais está a experiência formativa no âmbito das Escolas Família Agrícola (EFA). As EFA têm na pedagogia de alternância um dos eixos centrais de sua 
proposta formativa. Tal proposta chegou ao Brasil na década de 1960, no Estado do Espírito Santo e "implica em um processo de formação que combina e articula períodos de vivência no meio escolar e no meio familiar. Alterna-se, assim, a formação agrícola na propriedade com a formação teórica geral na escola [...]" (Silva, H. L., 2008, p. 108). Esta alternância entre a formação na escola - tempo-escola - e a formação na comunidade de origem do educando - tempo-comunidade - constitui-se num traço fundamental da proposta de alternância (Gimonet, 2007).

A escola do campo é entendida conforme Cardoso e Araújo (2012, p. 1) como "lugar em que se produz conhecimento a partir da relação direta com a cultura que os sujeitos estabelecem entre si e com o meio onde vivem", logo a educação do campo valoriza o sujeito do campo, seus saberes, sua cultura, e busca produzir conhecimento a partir desses aspectos. $\mathrm{O}$ ensino de ciências não pode ser alheio a esse traço que fundamenta a prática educacional nas escolas do campo. O currículo deve ser organizado de forma a trabalhar a realidade dos campesinos e assim contribuir para o desenvolvimento de senso crítico e reflexivo. Corroborando esse pensamento Lima (2011, p. 4) afirma que:

Os saberes e conhecimentos abordados no currículo das escolas do campo, além de terem uma relação direta com as vivências e as experiências dos jovens, devem possibilitar o desenvolvimento de competências e habilidades voltadas para o desenvolvimento das atividades sociais, culturais e produtivas no meio rural.

Contudo são vários os desafios impostos à contextualização do ensino de ciências à realidade do campo, conforme apresentam Novais, Fonseca, Freitas e Milli (2016), obstáculos que vão desde a estrutura curricular ao desinteresse dos alunos por esta área. Outro fator relevante acerca da contextualização do Ensino de Ciências está ligado à dificuldade que os alunos têm em relacionar o que aprendem na escola com o que vivenciam fora dela. Desse modo, o currículo deve ser elaborado a partir do contexto dos educandos, daquilo que está próximo a eles, não devendo se ater apenas aos conhecimentos do livro didático que, muitas vezes, apresentam a ciência de forma reducionista sem lhe atribuir significado, colaborando com a descontextualização do ensino.

\section{Classificação intuitiva como recurso facilitador para o ensino da Biodiversidade animal}

Quando classificamos objetos em nosso dia a dia, basicamente utilizamos como critério o maior ou menor grau de semelhança entre o que pretendemos classificar. Segundo Mayr (1998), ao classificar basicamente reunimos em grupos objetos que apresentam características em comum. Contudo, tratando-se de classificações biológicas, critérios mais rigorosos precisam ser observados. Ao longo do tempo diferentes critérios amparados em distintas fundamentações filosóficas foram utilizados, a fim de se organizar de forma mais natural possível os seres vivos (Costa, \& Waizbort, 2013). O modelo que atualmente predomina, segundo Roma e Motokane (2007, p. 7) é a sistemática filogenética e sua metodologia, proposta por Hennig, que "visa à reconstrução 
da história evolutiva dos seres vivos, proporcionando hipóteses de parentesco, devido a uma atribuição evolutiva dos caracteres".

Independentemente do método empregado no meio científico o homem tem utilizado diferentes modos de classificação que expressam diferentes formas de entender e explicar o universo e os seres que nele vivem. Contudo, historicamente, o senso comum tem o discurso científico como sendo verdade absoluta e inquestionável, negando outras formas de saber. Este pensamento também influenciou o ensino de ciências, que prioriza o conhecimento científico, muitas vezes menosprezando os saberes tradicionais acumulados ao longo de anos pelas comunidades. É preciso considerar que o espaço da sala de aula não é culturalmente uniforme, pois é formado por pessoas que possuem valores e visões de mundo diferentes. Assim, ao menos duas culturas estão presentes: a científica representada pelos professores e a cultura do estudante (Baptista, 2010). Portanto, no processo de ensino, faz-se necessário articular e promover o diálogo entre esses saberes para que a construção do conhecimento não implique em negação e abandono dos conhecimentos prévios dos educandos, o que pode gerar conflitos e dificultar a aprendizagem.

Pensando nisso, acredita-se que a proposta de utilizar classificações intuitivas, derivada do modelo intuitivo de classificação conforme abordado por Amorim (1999, como citado em Ferreira, Brito, Ribeiro, Sales, \& Almeida, 2008), para abordar o tema da diversidade animal pode funcionar como dinamizadora e facilitadora do processo de ensino e, por sua vez, da aprendizagem. Na medida em que traz à tona o saber proveniente do cotidiano dos estudantes, produzidos na comunidade e pela comunidade.

Diante do exposto, recorreu-se aos princípios teórico-metodológicos da etnobiologia. Acredita-se que essa possa potencializar a contextualização do ensino, por ser uma ciência que essencialmente se ocupa em estudar os diferentes conceitos e conhecimentos produzidos por diferentes grupos sociais sobre questões biológicas (Posey, 1986).

Quanto aos aspectos metodológicos das pesquisas etnobiológicas, Costa (2008) discorre que esse é um campo relativamente novo, estando sua metodologia ainda em desenvolvimento. Contudo, sendo essa uma ciência tão ampla, é possível utilizar diversas abordagens. As pesquisas etnobiológicas podem ser aplicadas em diferentes situações, por exemplo, a conservação de recursos biológicos e a conservação de saberes que, segundo Posey (1986), constituem um patrimônio da cultura universal. Este autor destaca ainda que, numa pesquisa etnobiológica, é de suma importância que o pesquisador, ao ir a campo e lidar com outras culturas, não imponha sua cultura como sendo superior ou único conhecimento válido, mas sim observe sempre a compreensão e o respeito mútuo.

Partindo desses pressupostos, buscamos investigar o que estudantes inseridos no contexto da educação do campo sabem sobre animais e como os classificam. Trabalho semelhante foi realizado por Andrade, Tavares, Dumont, Silveira Júnior e Valadares (2014), com estudantes do Curso de Formação Intercultural para Educadores Indígenas 
da Faculdade de Educação da Universidade Federal de Minas Gerais (FIEI/UFMG). Nesse trabalho, a abordagem visou a compreensão dos modos de classificação dos seres vivos, avaliando e discutindo as diferenças em relação à classificação biológica, bem como a valorização dos conhecimentos populares e reconhecimento de que cada modo de entender a natureza tem utilidade em distintos contextos. Entendendo que os conhecimentos etnobiológicos podem ser apropriados para articular diferentes culturas e diferentes modos de conhecer e conceber a natureza, optamos por tomá-los como ponte pela qual se estabeleceria o diálogo de saberes durante a realização dessa pesquisa.

\section{Aspectos Metodológicos}

Este trabalho constitui-se como um dos frutos de um projeto de pesquisa e extensão desenvolvido junto à Escola Família Agrícola em estudo, que visa fortalecer o enraizamento de comunidades no território do sisal tomando como ponto de partida o desenvolvimento de um observatório de juventudes rurais na região sisaleira. Esse observatório tem como principal foco o desenvolvimento participativo de atividades articuladas que promovam a interlocução entre a comunidade escolar (estudantes, professores e profissionais de apoio) e acadêmicos (professores e estudantes universitários), de modo a produzir um acervo documental de pesquisa colaborativa.

Em concordância com o projeto, uma dessas atividades, desenvolvida em conjunto com a equipe pedagógica e coordenada pelos autores deste artigo, foi a proposição de oficinas de ciências, articuladas ao currículo da escola, de acordo com o método da pesquisa-ação.

Tal como propõe Tripp (2005), essa pesquisa-ação passou por uma importante fase de reconhecimento do contexto da pesquisa, de seus participantes e das atuais práticas. Por isso, buscamos conhecer sobre a educação do campo, seus marcos históricos, a prática do ensino de ciências e como contribuir para aprimorá-la nesse contexto. Ainda segundo o autor, a pesquisa-ação consiste em estratégias de caráter interativo que permitem a participação ativa de todos os envolvidos na pesquisa, possibilitando ao pesquisador utilizar sua pesquisa para aprimorar a sua prática. Isto porque ao investigar ele pode refletir sobre a ação, avaliá-la e planejar meios de modificá-la.

Para Tripp (2005), é possível identificar cinco modalidades de pesquisa-ação de acordo com a natureza do projeto de pesquisa. Acreditamos que a pesquisa que desenvolvemos engloba tanto aspectos de caráter técnico quanto de caráter prático. Técnico porque tomamos como referência uma atividade já existente (a proposta de utilizar classificações intuitivas, derivada do modelo intuitivo de classificação conforme abordado por Amorim, 1999, como citado em Ferreira et al., 2008), para realizar uma tentativa de melhorar a prática do ensino de diversidade animal numa escola do campo. Justamente por isso, ela também é de natureza prática, uma vez que estabelecemos nossos próprios critérios de investigação com base no grupo com o qual trabalhamos, buscando melhorar nossa prática à medida que implementamos nossa pesquisa-ação.

Foram desenvolvidas oficinas temáticas com os estudantes de duas séries do 
Ensino Fundamental da escola. Participaram desta intervenção 44 estudantes, das turmas de $7^{\circ}$ e $9^{\circ}$ anos do ensino fundamental. A escolha destas turmas se deu em virtude da organização do trabalho pedagógico na escola, atendendo a uma demanda formativa dos estudantes, apresentada em algumas das reuniões de planejamento das atividades do projeto, da qual participaram membros da equipe pedagógica da escola e membros da equipe executora do projeto. Assim, visando articular os objetivos do projeto às atividades planejadas na escola, as turmas de $6^{\circ}$ e $8^{\circ}$ anos participaram de oficinas sobre diversidade vegetal, enquanto as turmas de $7^{\circ}$ e $9^{\circ}$ anos participaram das oficinas sobre diversidade animal, aqui apresentadas.

As oficinas se deram no espaço-tempo do Serão, momento específico presente na proposta curricular da escola e descrito em seu Projeto Político Pedagógico, no qual os estudantes tem a oportunidade de dialogar com parceiros da escola, visando enriquecer sua formação integral, como parte diversificada do currículo. Desse modo, as oficinas foram inicialmente propostas pela equipe executora do projeto de extensão e adequadas em seus objetivos e metodologia em reuniões pedagógicas na escola.

De acordo com o calendário de alternância definido pela escola no ano letivo em que foi realizada a pesquisa, as turmas de $7^{\circ}$ e $9^{\circ}$ anos alternavam semanalmente seu tempo-escola, ou seja, enquanto uma turma se encontrava na escola, a outra desenvolvia suas atividades junto às comunidades de origem. Considerando este calendário, as atividades das oficinas foram inicialmente desenvolvidas com a turma do $9^{\circ}$ ano e, na semana seguinte, com a turma do $7^{\circ}$ ano.

Após adequação das propostas das oficinas, essas foram desenvolvidas em três momentos distintos descritos a seguir. Vale ressaltar que previamente os participantes foram esclarecidos sobre a pesquisa, concordaram em participar por meio de Termo de Consentimento - TCLE- e de Assentimento de participação para pesquisa - TALE, que foram assinados pelos estudantes e seus responsáveis legais após o projeto ter sido aprovado por um Comitê de Ética em Pesquisa.

No primeiro encontro, apresentamos a proposta da oficina "Bichos que Conhecemos" para as turmas. Os estudantes foram estimulados a escolher e citar um animal. Todos os animais citados foram listados no quadro para que os estudantes fossem incentivados a escolher animais diferentes. Os estudantes foram também convidados a elaborar desenhos sobre os animais que escolheram descrever. Concluídos os desenhos, cada um pôde se apresentar e mostrar seu desenho para os demais explicando o porquê de ter escolhido aquele animal. Após esse momento, todos os animais citados pelos estudantes foram sistematizados, bem como os escritos e desenhos que os estudantes fizeram sobre eles.

No segundo encontro, os estudantes foram orientados a se dividirem em grupos de cinco componentes e foi proposto o exercício de classificação dos animais listados por eles. Cada grupo foi identificado com uma letra, a fim de facilitar a análise dos dados: os grupos A, B e C, pertencentes ao $9^{\circ}$ ano, e os grupos D, E, F, G, H e I pertencentes ao $7^{\circ}$ ano. Tendo em mãos a listagem de animais citados na etapa anterior, bem como imagens 
retiradas de internet, solicitamos que agrupassem os animais, produzindo cartazes do modo que considerassem mais fácil ou mais interessante. Para contextualizar a proposta, utilizamos exemplos de organização e classificação que praticamos em nosso dia a dia, por exemplo, a disposição de livros em bibliotecas. Após esse momento, os estudantes puderam apresentar seus agrupamentos (suas classificações) aos demais colegas, explicando quais critérios utilizaram para realizar a proposta.

No terceiro encontro, realizamos uma breve apresentação sobre o sistema de classificação científico e o método utilizado atualmente para classificar os seres vivos, com base na sistemática filogenética. Apresentamos ainda aos alunos um cladograma para exemplificar alguns termos, por exemplo, grupo monofilético, sinapomorfia, ancestral comum, a fim de familiarizar os estudantes com a linguagem filogenética. Também, distribuímos os livretos que produzimos a partir da sistematização da lista de animais, das classificações intuitivas feitas pelos estudantes e da classificação científica, o qual utilizamos para criar um espaço para o diálogo de saberes, estimulando os estudantes a perceber distintos modos de agrupar os seres. Neste último encontro ocorreu a culminância da oficina, com a socialização das produções dos estudantes para toda a escola.

Todos os encontros foram gravados em áudio e/ou vídeo e documentados por meio de fotografias, para que pudesse ser feita a posterior análise do todo processo desenvolvido junto aos alunos. Assim, todos estes registros são fontes de dados para as análises desta pesquisa. Vale ressaltar que em todo o processo de transcrição das falas ou dos escritos dos participantes, atentamos para a fidelidade ao que foi dito e escrito, reduzindo ao máximo a interferência nas produções dos estudantes.

Como principal técnica de análise de dados, utilizamos a Análise de Conteúdo apresentada por Bardin (2004), para análise das narrativas advindas das transcrições das gravações e dos escritos dos estudantes, considerando e respeitando as interações discursivas entre estudantes e pesquisadores. Seguindo tal técnica, os dados obtidos nessa pesquisa foram submetidos a uma pré-análise, que se trata da organização do material a ser analisado, da transcrição na íntegra das gravações e textos escritos dos estudantes e também dos cartazes com as classificações. A fase seguinte foi de exploração do material. Tal fase consistiu na codificação dos dados, que "é o processo pelo qual os dados brutos são transformados sistematicamente e agregados em unidades, as quais permitem uma descrição exacta das características pertinentes do conteúdo" (Bardin, 2004. p. 103). Durante a fase de exploração foram definidas as categorias de análise a partir das falas dos estudantes. Nenhuma categoria foi previamente definida, os estudantes tiveram total liberdade para escolher os critérios de classificação e dar nomes aos grupos definidos, se assim achassem interessante. As informações foram organizadas em: grupos de animais citados, critério de escolha desses animais e, por fim, critérios de classificação. A terceira e última fase consiste no tratamento dos resultados, que inclui a inferência e a interpretação dos dados. A seguir apresentamos alguns resultados produzidos a partir da oficina. 


\section{Resultados e discussão}

Tendo como pressuposto a compreensão de que o conhecimento culturalmente aprendido influencia a forma como o ser humano enxerga e interage com os animais, utilizamos a perspectiva etnozoológica a fim de responder à questão que norteou esse trabalho. Partimos da investigação acerca dos conhecimentos que os estudantes da EFA apresentam sobre animais que fazem parte ou não do seu cotidiano e quais sistemas e critérios utilizam para classificá-los. Os dados são apresentados e discutidos em conformidade com a sequência de momentos apresentados na metodologia.

\section{Oficina "Bichos que conhecemos"}

O ser humano interage de diversas formas com o meio que o circunda. Essa diversidade de interações se dá também na forma como se relaciona com as outras espécies. As relações estabelecidas podem variar desde a admiração até a aversão. Isso se explica pela hipótese da Biofilia, a qual apoia que o homem teve seu processo evolutivo intimamente associado a outros seres vivos, o que permitiu o desenvolvimento de uma ampla rede de informações que deu origem aos saberes culturais sobre a fauna (SantosFita, \& Costa Neto, 2007). Esses conhecimentos aprendidos em casa e em outros locais de convívio dos estudantes chegam à sala de aula e, como apresentado anteriormente, podem ser utilizados a fim de permitir que o aluno construa conceitos a partir do que sabe sobre a natureza. As Figuras 1 e 2 apresentam os animais citados durante a primeira etapa pelas turmas participantes.

\begin{tabular}{|l|l|}
\hline Nome popular & Espécie/Gênero/Família/Ordem \\
\hline Crocodilo & Família Crocodylidae Laurenti, 1768 \\
\hline Arara & Família Psittacidae Rafinesque, 1815 \\
\hline Macaco & Infraordem Simiiformes Haeckel, 1866 \\
\hline Baleia & Superfamília Mysticeti Flower, 1864 \\
\hline Cobra cascavel & Crotalus durissus Lineu, 1758 \\
\hline Papagaio & Amazona sp. Lesson, 1830 \\
\hline Elefante & Família Elephantidae Grey, 1821 \\
\hline Arara azul & Anodorhynchus sp. Spix, 1824 \\
\hline Tatupeba & Euphractus sexcintus Linnaeus, 1758 \\
\hline Mosca & Superfamília Muscoidea \\
\hline Barata & Periplaneta sp. Burmeister, 1838 \\
\hline Guepardo & Acinonyx jubatus Schreber, 1775 \\
\hline Leopardo & Panthera pardus Linnaeus, 1758 \\
\hline Formiga & Família Formicidae Latreille, 1809 \\
\hline Aranha & Família Theraphosidae Thorell, 1869 \\
\hline Carneiro & Ovis aries Linnaeus, 1758 \\
\hline Mocó & Kerodon rupestres Wied-Neuwied, 1820 \\
\hline
\end{tabular}

Figura 1. Animais citados pela turma do $7^{\circ}$ ano (continua) 


\begin{tabular}{|l|l|}
\hline Nome popular & Espécie/Gênero/Família/Ordem \\
\hline Coelho & Família Leporidae Fischer, 1817 \\
\hline Saruê & Didelphis aurita Wied-Neuwied, 1826 \\
\hline Camaleão & Iguana iguana Linnaeus, 1758 \\
\hline Nico & Callithrix sp. Erxleben, 1777 \\
\hline Canguru & Macropus sp. Shaw, 1790 \\
\hline Cutia & Dasyprocta sp. Illiger, 1811 \\
\hline Tucano & Ramphastos toco Statius Muller, 1776 \\
\hline Golfinho & Delphinus sp. Linnaeus, 1758 \\
\hline Girafa & Giraffa sp. Brisson, 1762 \\
\hline Canário & Serinus sp. Koch, 1816 \\
\hline Camelo & Camelus sp. Linnaeus, 1758 \\
\hline Camarão & Superfamília Penaeoidea Rafinesque, 1815 \\
\hline
\end{tabular}

Figura 1. Animais citados pela turma do $7^{\circ}$ ano (continuação)

O primeiro ponto a destacar nessa etapa é a escolha dos animais. Intencionalmente foi proposto que cada "bicho" só poderia ser escolhido uma única vez, para incentivá-los a pensar sobre a diversidade existente. O uso da palavra "bicho" nesse momento também foi intencional, pois consideramos que usar a palavra "animal" poderia restringir a escolha dos estudantes, uma vez que muitos não entendem seres vivos como insetos, por exemplo, como sendo animais. E alguns grupos categorizam a fauna entre bicho e animal, sendo que o primeiro termo se refere a animais silvestres, ou bicho do mato, e o segundo, a animais domésticos (Pinto, 2011).

\begin{tabular}{|l|l|}
\hline Nome popular & Espécie/Gênero/Família \\
\hline Porco & Sus scrofa Linnaeus, 1758 \\
\hline Boi & Bos taurus Linnaeus, 1758 \\
\hline Jacaré & Família Alligatoridae Gray, 1844 \\
\hline Sapo & Família Bufonidae Grey, 1825 \\
\hline Jegue & Equus asinus Gray, 1824 \\
\hline Teiú & Tupinambis sp. Daudin, 1803 \\
\hline Onça-pintada & Panthera onca Linnaeus, 1758 \\
\hline Leão & Panthera leo Linnaeus, 1758 \\
\hline Coruja & Família Strigidae Leach, 1820 \\
\hline Bacalhau & Gadus sp. Linnaeus, 1758 \\
\hline Cabra & Capra hircus Linnaeus, 1758 \\
\hline Tubarão & Superordem Selachimorpha \\
\hline Cachorro & Canis lupus familiaris Linnaeus, 1758 \\
\hline Gato & Felis catus Linnaeus, 1758 \\
\hline Cavalo & Equus caballus Linnaeus, 1758 \\
\hline
\end{tabular}

Figura 2. Animais citados pela turma do $9^{\circ}$ ano 
A proporção em que são representados os distintos grupos taxonômicos (categorias de classificação) entre os bichos escolhidos pelos estudantes é um dado importante a ser destacado. A partir das informações obtidas no primeiro momento da oficina, é possível inferir que mamíferos constituem o grupo mais amplamente conhecido, pois foram os mais citados, $26 \mathrm{em}$ um total de 44 . Em segundo lugar se encontram as aves, citados por 6 estudantes.

Apesar do foco dessa pesquisa não ser quantitativo, esse dado é expressivo e pode estar diretamente ligado à forma como os estudantes se relacionam com esses grupos. Os animais mais citados foram aqueles que apresentam uma ampla utilização, seja na alimentação, ou como animais domésticos, aos quais se atribui valor afetivo ou econômico. Resultado semelhante foi obtido por Oliveira e Souza (2014), em uma pesquisa também de cunho etnozoológico, em que mamíferos e aves foram, também, os grupos mais citados pelos participantes. Tal afirmação se confirma ao analisar as justificativas dadas pelos estudantes para a escolha dos respectivos animais, por exemplo, a escolha de 13 dos 26 mamíferos citados está diretamente ligada ao fato de o animal ser usado na alimentação, por apresentar valor econômico, afetivo ou cultural. Isto pode ser observado nos desenhos elaborados pelos estudantes durante esta primeira etapa da oficina, bem como as justificativas de sua escolha por estes animais.

A onça (Panthera onca L.) e o crocodilo (Família Crocodylidae) se enquadram no conjunto de animais que foram escolhidos porque, de alguma forma, despertam interesse, curiosidade, chamam atenção por sua agilidade, pelo tamanho, porque são predadores hábeis, ferozes (essas foram palavras usadas pelos alunos para descrever os "bichos" escolhidos), a exemplo:

Eu não fiz um desenho mas escrevi. O guepardo é um animal muito espetacular por muitos aspectos, tais como, ele é o animal mais rápido do mundo entre todos, ele é um mamífero muito surpreendente, ele pode dobrar sua coluna vertebral em um ângulo de 90 graus para ter uma melhor agilidade, também serve pra fazer curvas rápidas, capturar as presas, quando estiver caçando seu alimento, Ele também consegue subir em árvores para dormir ou descansar e também ficar observando o movimento ao seu redor. (Estudante do $7^{\circ}$ Ano)

Uma das explicações para essa admiração por certos animais segundo Dunker (2016) se dá pelo fato de que eles evocam traços com os quais nos identificamos e os grandes felinos exercem essa atratividade por serem símbolo de coragem, força, agilidade, elementos que o ser humano gostaria de reter para si.

Com relação ao Tatupeba (Euphractus sexcintus L.), o aluno atribui a escolha do animal por esse ser utilizado na alimentação, destacando que ele é "muito gostoso". Trabalhos já mencionados também citam o uso de animais silvestres, inclusive o próprio tatupeba, tanto para consumo por parte daqueles que caçam quanto para comercialização da carne desses animais. Silva (2016) propõe que o uso da fauna por uma determinada comunidade pode estar ligado às condições socioeconômicas e culturais da comunidade e para muitas, aves e principalmente mamíferos representam uma fonte de renda e 
alimento; a prática da caça é comum em muitas comunidades do semiárido nordestino.

O senso de pertencimento cultural também se evidencia nas falas e desenhos; alguns estudantes justificaram a escolha do animal por esse de alguma forma caracterizar aspectos próprios do seu contexto cultural. Foi o caso da escolha do Cavalo (Equus caballus L.), do boi (Bos taurus) e do jegue (Equus asinus Gray). O boi está fortemente ligado à cultura local, uma vez que o próprio nome do município tem origem em um mito datado do século XX que narra a história de um "boi valente". Este animal, assim como o cavalo, representa um traço cultural muito forte na região, a vaquejada, símbolo de entretenimento e fonte de renda para seus moradores.

A pecuária, atividade estabelecida e disseminada no território de caatinga ainda na época do Brasil império, além de introduzir o boi como elemento cultural, deu origem à figura do vaqueiro, do sertanejo, figuras também características que carregam marcas de uma tradição propagada de geração a geração, sobre a força e luta de um povo para viver em um ambiente que lhes impunha condições extremamente adversas (Valle, 2007). Segundo a referida autora, a tradicional vaquejada tem origem em uma das atividades realizadas pelo vaqueiro, conhecida como "pega de boi", palco onde tal personagem desempenha com "temor" e "paixão" sua função.

O desenho apresentado na Figura 3, também associado ao senso de pertencimento e valorização da terra e de seus elementos, demonstra que diferentes referências se articulam quando se trata de representar determinado local. Ao ser questionado quanto ao motivo de sua escolha, o estudante informa "Eu escolhi o jegue porque ele representa nossa região sisaleira”.

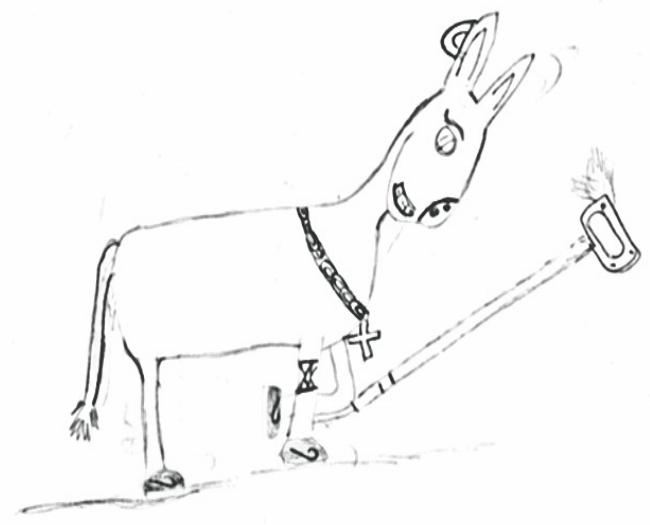

Figura 3. Jegue (Equus asinus Gray).

O município no qual se insere a escola está localizado no Território de Identidade do Sisal, mais comumente conhecido por região sisaleira, pela importância econômica desta planta em diversos municípios do nordeste da Bahia. Por outro lado, o município é conhecido historicamente por um mito de origem que tem um boi como símbolo identitário (Freixo, 2010). Por outro lado, a figura do jegue se associa à região sisaleira pelo fato de esse ser um animal muito utilizado no transporte de carga. Mais uma vez a imagem de um animal está relacionada à cultura e identidade local, reforçando a 
ideia de que a história da humanidade se constrói intimamente associada e fortemente influenciada pelas relações estabelecidas com os demais animais. Um detalhe que merece ser destacado no desenho é que o jegue está fazendo uma selfie. Isso remete ao fato de que a cultura é dinâmica e que, ao passo que certos elementos permanecem como sendo característicos, outros são abandonados e novos elementos vão sendo acrescentados a esse complexo conjunto de símbolos que se integram para formar o que entendemos por cultura. Assim, a imagem combina diferentes traços, unindo um passado que é extremamente presente, uma história que não está apenas na memória, mas que ainda é vivenciada por muitos, inclusive pelos próprios estudantes da EFA, que acabam por agregar a essas representações historicamente construídas um novo significado.

As aves, segundo grupo mais citado pelos estudantes, também foram escolhidas pela admiração que os estudantes manifestam por esses animais, de modo semelhante aos mamíferos. Como exemplo, temos o Canário (Serinus sp.), que foi escolhido pela estudante por chamar atenção pela aparência e pelo canto.

A utilização de aves como animal de estimação também é mencionada por Silva (2016) e Alves, Mendonça, Confessor, Vieira e Lopez (2009), que destacam que essa é uma prática muito comum no semiárido nordestino, compondo a identidade de vários grupos sociais nessa região. Tal prática, por motivo de subsistência ou outros motivos, como esporte e lazer, consiste em uma das principais ameaças à fauna local. Mesmo relatando o uso de animais silvestres para alimentação, a exemplo do Tatupeba, ou como animal de estimação, alguns estudantes demonstraram consciência de que várias espécies estão em extinção, sobretudo por conta da caça e comércio ilegal. Este é o caso do estudante que escolheu apresentar a Arara Azul (Anodorhynchus hyacinthinu Latham).

Essa noção de que espécies estão desaparecendo, sobretudo devido à ação humana, demonstra que os estudantes estão sensíveis aos problemas ambientais que os cercam, como o desaparecimento de espécies, por exemplo, sendo conscientes quanto à necessidade de conservação da natureza. E isto não porque a veem de forma isolada, mas porque se sentem parte dela e em seu dia a dia estão sempre em contato íntimo com ela e reconhecem a relação de interdependência entre o ser humano e o meio que o circunda, com todos os elementos que os constituem. Esse aspecto pode ser atribuído ao fato de que a escola propicia um contexto educacional que possibilita a formação integral dos estudantes em que, dentre outras preocupações, está a formação do jovem agricultor quanto ao aspecto ecológico, bem como a promoção de práticas que promovam o desenvolvimento local de forma sustentável.

Esse interesse em promover práticas de uso adequado tanto da fauna quanto de recursos naturais, aliado aos saberes tradicionais sobre manejo destes recursos, pode muito contribuir para a conservação da biodiversidade. Estudos de caráter etnozoológico (Pinto, 2011; Torres, Rodrigues, \& Barreto, 2015) têm apontado que o conhecimento tradicional é de grande valia quando se fala em conservação, pois essas comunidades tradicionais possuem muito conhecimento sobre a fauna e reconhecem que esses 
recursos são importantes para a sua subsistência.

É notável que enquanto muitos manifestaram admiração e simpatia para com alguns animais, outros expressaram sentimento oposto, alguns alunos atribuem características negativas e demostram ter aversão por certos animais, especificamente aos que pertencem ao grupo dos insetos.

A barata é um inseto nojento e feio que gosta de ficar em lugares sem movimento, por exemplo, tem umas baratas que dão atrás do guarda roupa dentro das roupas, e assim eu escolhi ela por que me veio na mente. (Estudante do $7^{\circ}$ Ano)

Uma aluna, mesmo atribuindo caraterísticas negativas, reconhece que o animal escolhido, a mosca, é importante na natureza e que os seres vivos são interdependentes.

A mosca é um animal nojento que pousa nas fezes e depois pousa na comida da gente com suas patas sujas e pousa na pessoa toda hora se a pessoa estiver melada, elas são minúsculas e feias. As moscas tem várias diversidades. Tem a famosa mosca azul aquela que produz um negocinho nojento, uma gosminha. A mosca minúscula aquelas que ficam lá no banheiro sujo, nos banheiros da escola e as pretas, e várias outras. Eu escolhi a mosca por que a gente precisa dela para o ciclo da vida. (Estudante do $7^{\circ}$ Ano)

É evidente o contraste entre as expressões utilizadas para caracterizar os mamíferos e os insetos. Para os primeiros os alunos utilizaram carinhoso, cuidadoso, gentil, fofinhos, enquanto que para os insetos fizeram uso de expressões depreciativas como "feio" e "nojento", revelando que os estudantes possuem uma visão preconceituosa sobre os insetos, visão essa que parece permear o imaginário de grande parte da população. Em uma pesquisa que buscou identificar as representações sociais de estudantes do ensino médio sobre insetos, Trindade, Silva Júnior e Teixeira (2012) identificaram que grande parte $(78,8 \%)$ dos participantes associaram expressões e/ou sentimentos negativos aos insetos, inclusive termos também mencionados aqui como feio e nojento, sendo muitas vezes referidos apenas como causadores de danos e transmissores de doenças. Tais resultados se assemelham aos encontrados aqui, no sentido das representações negativas, mesmo sendo o grupo taxonômico mais diverso e abundante.

É preciso destacar que o ensino de ciências desempenha papel de suma importância na forma como estudantes percebem e se relacionam com os demais seres vivos. Pensando nisso, um meio de contribuir com a desconstrução de uma visão pejorativa sobre determinados grupos seria a problematização em aula da perspectiva antropocêntrica e utilitarista que pauta a relação homem e demais espécies (Trindade; Silva Junior, \& Teixeira, 2012), realizando uma abordagem que enfatize a importância ambiental, os aspectos ecológicos, e evolutivos dos seres vivos ao invés da tradicional memorização de nomes e grupos.

\section{Classificações intuitivas}

Independentemente do método empregado no meio científico, os seres humanos têm utilizado diferentes modos de classificação que expressam diferentes formas de 
entender e explicar o universo e os seres que nele vivem. O campo da etnobiologia que se ocupa do estudo das classificações naturais feitas por comunidades tradicionais denomina-se Etnotaxonomia e, entre outras questões, busca entender como diferentes grupos sociais classificam os seres vivos a partir das suas percepções e das relações estabelecidas com estes seres.

Antes de apresentar as classes criadas é preciso ressaltar que justamente por serem estudantes do $7^{\circ}$ e $9^{\circ}$ ano do ensino fundamental, estes já tiveram contato com o conteúdo em questão. Por isso suas classificações não são totalmente destituídas dos conceitos e terminologias utilizadas na linguagem científica.

Nove grupos de estudantes foram formados e cada um propôs uma classificação utilizando seus próprios critérios e categorias. As classificações feitas pelos grupos de estudantes do $9^{\circ}$ ano aparecem na Figura 4 . O critério utilizado pelo grupo A resultou em duas categorias: domésticos e selvagens, que revelam a forma como esses animais são percebidos.

\begin{tabular}{|c|c|c|}
\hline $\mathrm{A}$ & $\mathrm{B}$ & C \\
\hline \multirow{3}{*}{$\begin{array}{l}\text { Domésticos: Cachorro, } \\
\text { cavalo, coelho, mocó, } \\
\text { tucano, canário, papagaio, } \\
\text { nico, jegue, gato, vaca, cabra, } \\
\text { porco, carneiro, arara, peixe, } \\
\text { arara azul. }\end{array}$} & $\begin{array}{l}\text { Domésticos: Cavalo, cachorro, coelho, } \\
\text { gato, nico, jegue. }\end{array}$ & $\begin{array}{l}\text { Répteis: Jacaré, Teiú, } \\
\text { camaleão, cobra, crocodilo. }\end{array}$ \\
\hline & \multirow{2}{*}{$\begin{array}{l}\text { Selvagens: Camaleão, leopardo, } \\
\text { camelo, girafa, carneiro, elefante, } \\
\text { guepardo, onça, cobra, jacaré, tatu, } \\
\text { crocodilo, canguru, macaco, cutia, } \\
\text { mocó saruê, teiú. }\end{array}$} & $\begin{array}{l}\text { Anfíbios: Sapo, tatu, } \\
\text { camarão. }\end{array}$ \\
\hline & & $\begin{array}{l}\text { Insetos: mosca, grilo, } \\
\text { aranha, formiga. }\end{array}$ \\
\hline \multirow{5}{*}{$\begin{array}{l}\text { Selvagens: Coruja, onça, } \\
\text { guepardo, leão, ornitorrinco, } \\
\text { elefante, teiú, mosca, } \\
\text { tubarão, aranha, saruê, } \\
\text { baleia, sapo, jacaré, golfinho, } \\
\text { leopardo, cutia, tatu, grilo, } \\
\text { formiga, camarão, cabra, } \\
\text { canguru, camelo, girafa, } \\
\text { macaco. }\end{array}$} & $\begin{array}{l}\text { Aves: Tucano, arara, coruja, papagaio, } \\
\text { canário. }\end{array}$ & \multirow{3}{*}{$\begin{array}{l}\text { Mamíferos: Leão, girafa, } \\
\text { coelho, jegue, onça, cutia, } \\
\text { cavalo, nico, cabra, carneiro, } \\
\text { elefante, baleia, camelo, } \\
\text { porco, cachorro, vaca, gato, } \\
\text { saruê, macaco, ornitorrinco, } \\
\text { guepardo, leopardo, mocó, } \\
\text { golfinho. }\end{array}$} \\
\hline & De produção: Porco, boi, cabra. & \\
\hline & $\begin{array}{l}\text { Aquáticos: camarão, bacalhau, } \\
\text { golfinho, tubarão, baleia, } \\
\text { ornitorrinco. }\end{array}$ & \\
\hline & \multirow[b]{2}{*}{$\begin{array}{l}\text { Nojentos (invertebrados): formigas, } \\
\text { aranha, sapo, mosca, grilo. }\end{array}$} & Peixes: Bacalhau, tubarão. \\
\hline & & $\begin{array}{l}\text { Aves: Arara azul, coruja, } \\
\text { canário, papagaio, tucano. }\end{array}$ \\
\hline
\end{tabular}

Figura 4. Classificações feitas pelos grupos A, B e C, de estudantes do $9^{\circ}$ ano

O significado que naturalmente se atribui a animal selvagem é o do animal que vive livre em seu habitat e que possui um instinto agressivo em relação às pessoas, enquanto que animal doméstico é aquele que pertence ao convívio do lar, também denominado de animal de estimação. Para verificar a compreensão que os estudantes 
possuem sobre selvagem e doméstico e se essa ideia corresponde ao senso comum foi feita a seguinte pergunta:

Pesquisadora: Só uma pergunta: o que vocês pensam que é doméstico e selvagem? Só pra eu saber o porquê de vocês terem classificado assim.

Estudante: Selvagens são todos os animais que atacam, o leão, a onça, a cobra.

Apesar de não ter obtido a resposta sobre o que eles entendem por animal doméstico, é possível inferir por meio dos animais incluídos nessa categoria que o conceito deles repousa sobre o senso comum, do animal que é criado em casa como o gato e o cachorro ou próximo a ela e que também está habituado ao convívio com pessoas, como o cavalo, porco, boi, carneiro etc. Tais animais, como discutido anteriormente, pertencem ao convívio dos estudantes, uma vez que a criação de gado e a caprinocultura são atividades expressivas na região. De acordo com essa classificação, pertencem também ao grupo dos domésticos as aves que também são muito utilizadas como animal de estimação, sobretudo na região, devido à aparência e ao canto.

Como é possível notar, o grupo dos selvagens é bem diverso quanto às espécies enquanto que o grupo dos domésticos é constituído apenas por aves e mamíferos, os dois grupos mais citados na etapa anterior. Já o grupo dos selvagens além de mamíferos e aves inclui também aracnídeos, insetos, répteis, peixes (tubarão), reforçando a ideia de que selvagem é o animal que vive livre na natureza, que é feroz, predador, que ataca o homem, como mencionado pelos estudantes.

Crocodilo porque além de ser grande é um animal feroz e ele pode atacar dependendo do lugar, por exemplo, você vai numa selva e encontra um, dependendo do lugar que você tentar mexer nele ele vai conseguir atacar por isso que eu gosto dele.

O leopardo porque é predador e é pintado.

O tubarão porque mesmo sendo um peixe feroz ele alimenta outros tipos de peixe com sobras do alimento que ele come.

O grupo B, além das categorias já mencionadas (selvagense domésticos), utilizando mais critérios, criou as categorias "nojentos" e "animais de produção", pertencendo ao primeiro grupo a aranha, o sapo, formiga, grilo e a mosca; e a segundo o porco, o boi e a cabra, indicando a percepção e a relação que eles possuem com os animais classificados nesses grupos.

O agrupamento denominado de "nojentos" corrobora o que foi apresentado no tópico anterior sobre a visão pejorativa e preconceituosa para com alguns animais, especialmente os que pertencem ao grupo dos insetos, mas que não se restringe apenas a esse grupo. Os estudantes incluíram no grupo o sapo, que diferente dos outros animais inclusos no mesmo grupo por ser um vertebrado, pertencente a ordem Anura, que também causam a sensação de repulsa e nojo em muitos por conta da aparência e textura da pele. Essa atribuição de características negativas faz com que com animais que 
pertençam a grupos taxonômicos distintos sejam colocados em uma mesma categoria quando classificados intuitivamente.

O agrupamento "animais de produção" reflete a relação que é estabelecida com esses animais, pois para aqueles que vivem no campo e dependem dos seus recursos, a criação de animais é um meio de subsistência e fonte de renda. Em relação ao grupo A, que em uma única categoria inclui os domésticos de estimação e os aqui ditos de produção, o grupo B criou uma categoria específica para esses animais, caracterizandoos como animais que produzem e, de alguma forma, servem ao interesse humano. Tal classificação pode refletir o caráter utilitarista e antropocêntrico em relação a determinados animais.

Alguns agrupamentos não constituem grupos válidos taxonomicamente, como répteis e peixes, pois não se tratam de grupos monofilético (grupo que inclui um ancestral e todos os seus descendentes), mas de vários animais que podem ser coletivamente designados por esses termos. Sobre os répteis, alguns detalhes são considerados posteriormente. Em relação às aves, no geral os alunos não tiveram dificuldade para reuni-las em um grupo, excetuando o grupo A que as reuniu no grupo de animais domésticos. Em todos os outros, elas constituem uma categoria à parte, talvez pelas características exclusivas que o grupo apresenta como os membros anteriores em forma de asa e presença de penas.

Sobre a classificação do grupo C, voltamos nossa atenção para o grupo denominado de "insetos", formado pela mosca, grilo, formiga e a aranha, pertencente ao grupo dos aracnídeos, mas agrupada juntamente com os insetos. Como trabalhamos classificações intuitivas, os agrupamentos propostos pelos estudantes expressam a forma como esses animais são percebidos, como é o caso do grupo "insetos".

Costa Neto e Pacheco (2004) investigaram a construção do domínio etnozoológico "inseto" pelos moradores de um povoado no Estado da Bahia e constataram que a etnocategoria inseto reúne organismos não taxonomicamente relacionados, como o rato, rã, escorpião e a aranha (entre outros), destacando ser comum essa forma de classificar os insetos em diversos contextos culturais. Geralmente as pessoas atribuem a insetos características de conotação negativa, como animais nojentos, insignificantes, feios, que incomodam, pragas que prejudicam o homem, e transferem essas características a outros animais, não relacionados à categoria taxonômica inseto. Segundo Costa Neto (2000, p.71), essa atitude se explica pela hipótese da ambivalência entomoprojetiva "segundo a qual os seres humanos tendem a projetar sentimentos de nocividade, periculosidade, irritabilidade, repugnância e menosprezo a animais não-insetos (inclusive pessoas), associando-os à categoria "inseto" determinada culturalmente".

Alguns agrupamentos demonstram a dificuldade que os estudantes tiveram ao classificar os animais: o agrupamento definido como "anfíbios" na classificação feita pelo grupo C é um exemplo dessa dificuldade. Esse agrupamento, além do sapo, inclui o tatu e o camarão. Os estudantes justificaram que o camarão, por não possuir as características típicas de um peixe, foi agrupado na categoria "anfíbio". Quanto ao tatu, os estudantes o 
distinguem em muitos aspectos dos demais mamíferos, classe à qual taxonomicamente pertence. Uma vez estabelecidas as categorias, o que alguns alunos fizeram foi distribuir aleatoriamente os animais que, para eles, não satisfaziam os critérios estabelecidos para pertencer a tal grupo.

Por fim, destacamos as diferenças entres as três classificações feitas pela turma do $9^{\circ}$ ano em relação ao emprego das categorias taxonômicas: $\mathrm{O}$ grupo A utilizou apenas duas categorias para agrupar os 44 animais citados, enquanto os grupos $\mathrm{B}$ e C definiram mais categorias. No entanto, as classificações feita pelos Grupos A e B se aproximam mais do que se entende por etnocategoria, pois parecem refletir melhor a forma como esses animais são percebidos expressando a relação existente entre eles. Por outro lado, o grupo $\mathrm{C}$ definiu categorias que correspondem às apresentadas nos livros de Ciências e Biologia. Foram definidos cinco agrupamentos, "répteis", "anfíbios", "insetos", "mamíferos", "peixes" e "aves", refletindo uma maior mobilização do saber científico ao classificar os animais.

Os estudantes do $7^{\circ}$ ano definiram mais categorias (Figura 5) e realizaram mais agrupamentos. Algumas dessas categorias aparecem em praticamente todas as classificações, a exemplo da categoria "mamíferos" que, mesmo não tendo sido especificada em alguns cartazes, foi mencionada por praticamente todos os grupos de estudantes durante as apresentações.

Muitos estudantes tiveram dificuldade em agrupar certos animais, fazendo com que aqueles que não se encaixavam nas categorias estabelecidas fossem distribuídos aleatoriamente.

Um exemplo dessa distribuição aleatória foi percebida na classificação feita pelo grupo D, na qual o tubarão foi colocado no grupo dos mamíferos. Mesmo os estudantes concordando que ele não pertence a essa categoria, ao apresentar o cartaz eles justificaram: “Todos aqui são mamíferos, menos o tubarão, mas todos aqui são mamíferos". Como o grupo havia definido a categoria "frutos do mar" contendo bacalhau e camarão, o tubarão não se encaixava nesse agrupamento, por isso foi incluído no grupo dos mamíferos.

Corroborando o que foi dito sobre como diferentes grupos sociais classificam alguns animais, em virtude da forma como estes são percebidos, todos os grupos do $7^{\circ}$ ano classificaram a aranha como inseto, com exceção do grupo $\mathrm{D}$, que reconheceu a aranha como aracnídeo. 


\begin{tabular}{|c|c|c|c|c|c|}
\hline $\mathrm{D}$ & E & F & G & $\mathrm{H}$ & I \\
\hline \multirow{7}{*}{$\begin{array}{l}\text { Mamíferos: } \\
\text { Golfinho, tubarão, } \\
\text { baleia, canguru, } \\
\text { elefante, jegue, } \\
\text { camelo, girafa, nico, } \\
\text { macaco, saruê, } \\
\text { cachorro, coelho, } \\
\text { cavalo, porco, } \\
\text { carneiro, mocó, } \\
\text { cabra, boi. }\end{array}$} & \multirow{2}{*}{$\begin{array}{l}\text { Aves: Arara, } \\
\text { coruja, canário, } \\
\text { tucano, papagaio, } \\
\text { arara azul. }\end{array}$} & \multirow{2}{*}{$\begin{array}{l}\text { Arara azul, } \\
\text { canário, } \\
\text { papagaio, } \\
\text { coruja. }\end{array}$} & $\begin{array}{l}\text { Cavalo, jegue, } \\
\text { cabra, carneiro, } \\
\text { porco, boi. }\end{array}$ & \multirow{3}{*}{$\begin{array}{l}\text { Camarão, } \\
\text { Golfinho sapo, } \\
\text { bacalhau, baleia, } \\
\text { tubarão. }\end{array}$} & $\begin{array}{l}\text { Ferozes: Jacaré, } \\
\text { crocodilo, } \\
\text { tubarão, leão. }\end{array}$ \\
\hline & & & Macaco, nico. & & \multirow{3}{*}{$\begin{array}{l}\text { Cabra, carneiro } \\
\text { elefante, boi, } \\
\text { canguru, girafa, } \\
\text { jegue, cavalo. }\end{array}$} \\
\hline & \multirow{3}{*}{$\begin{array}{l}\text { Felinos: gato, leão, } \\
\text { onça, leopardo, } \\
\text { guepardo. }\end{array}$} & \multirow{3}{*}{$\begin{array}{l}\text { Aranha, } \\
\text { formiga, } \\
\text { mosca. }\end{array}$} & $\begin{array}{l}\text { Elefante, } \\
\text { girafa. }\end{array}$ & & \\
\hline & & & \multirow{4}{*}{$\begin{array}{l}\text { Baleia, } \\
\text { bacalhau, } \\
\text { tubarão, jacaré, } \\
\text { crocodilo } \\
\text { golfinho, } \\
\text { camarão. }\end{array}$} & Jacaré, teiú, & \\
\hline & & & & $\begin{array}{l}\text { cobra, crocodilo, } \\
\text { camaleão. }\end{array}$ & $\begin{array}{l}\text { Herbívoros: } \\
\text { Tatu, camaleão, }\end{array}$ \\
\hline & \multirow[b]{2}{*}{$\begin{array}{l}\text { Animais da } \\
\text { caatinga: mocó, } \\
\text { cutia, saruê, } \\
\text { coelho, tatu, } \\
\text { sapo. }\end{array}$} & \multirow[b]{2}{*}{$\begin{array}{l}\text { Canguru, } \\
\text { girafa, elefante, } \\
\text { camelo, }\end{array}$} & & & teiú, camelo. \\
\hline & & & & $\begin{array}{l}\text { Mosca, formiga, } \\
\text { aranha. }\end{array}$ & $\begin{array}{l}\text { Mosca, formiga, } \\
\text { aranha, grilo, } \\
\text { cobra }\end{array}$ \\
\hline \multirow{2}{*}{$\begin{array}{l}\text { Aves: Arara, coruja, } \\
\text { arara azul, canário, } \\
\text { papagaio, tucano. }\end{array}$} & \multirow{2}{*}{$\begin{array}{l}\text { Aquáticos: } \\
\text { camarão, } \\
\text { bacalhau, } \\
\text { golfinho, tubarão, } \\
\text { baleia. }\end{array}$} & \multirow{2}{*}{$\begin{array}{l}\text { Jegue, cavalo, } \\
\text { boi, carneiro, } \\
\text { cabra, porco. }\end{array}$} & \multirow{2}{*}{$\begin{array}{l}\text { Cachorro, } \\
\text { gato, onça, } \\
\text { guepardo, } \\
\text { leopardo, leão. }\end{array}$} & $\begin{array}{l}\text { Arara, papagaio, } \\
\text { arara azul, } \\
\text { canário, coruja. } \\
\end{array}$ & \multirow{2}{*}{$\begin{array}{l}\text { Marinhos: } \\
\text { baleia, } \\
\text { bacalhau, } \\
\text { golfinho, } \\
\text { camarão. }\end{array}$} \\
\hline & & & & $\begin{array}{l}\text { Mocó, coelho, } \\
\text { cutia. }\end{array}$ & \\
\hline $\begin{array}{l}\text { Insetos: formiga, } \\
\text { mosca. }\end{array}$ & $\begin{array}{l}\text { Répteis: jacaré, } \\
\text { camaleão, teiú, } \\
\text { cobra, crocodilo. }\end{array}$ & $\begin{array}{l}\text { Onça, } \\
\text { guepardo, } \\
\text { leopardo, leão. }\end{array}$ & $\begin{array}{l}\text { Coruja, arara, } \\
\text { canário, } \\
\text { papagaio, } \\
\text { tucano, arara } \\
\text { azul. }\end{array}$ & $\begin{array}{l}\text { Camelo, } \\
\text { girafa, elefante, } \\
\text { canguru. }\end{array}$ & $\begin{array}{l}\text { Macacos: } \\
\text { macaco, nico. }\end{array}$ \\
\hline \multirow{4}{*}{$\begin{array}{l}\text { Felinos: gato, onça, } \\
\text { leão, guepardo, } \\
\text { leopardo. }\end{array}$} & Suínos: porco. & Coelho, saruê. & \multirow{2}{*}{$\begin{array}{l}\text { Mosca, } \\
\text { formiga, } \\
\text { aranha. }\end{array}$} & \multirow{2}{*}{$\begin{array}{l}\text { Macaco, nico, } \\
\text { gato, cachorro. }\end{array}$} & \multirow{4}{*}{$\begin{array}{l}\text { Aves: arara } \\
\text { azul, papagaio, } \\
\text { coruja, arara, } \\
\text { canário, } \\
\text { tucano. }\end{array}$} \\
\hline & $\begin{array}{l}\text { Caninos: } \\
\text { cachorro. }\end{array}$ & Mocó, cutia. & & & \\
\hline & Bovinos: boi. & $\begin{array}{l}\text { Gato, } \\
\text { cachorro. }\end{array}$ & \multirow{2}{*}{$\begin{array}{l}\text { Tatu, mocó, } \\
\text { cutia, coelho, } \\
\text { saruê. }\end{array}$} & \multirow{2}{*}{$\begin{array}{l}\text { Leopardo, onça, } \\
\text { leão, guepardo }\end{array}$} & \\
\hline & $\begin{array}{l}\begin{array}{l}\text { Equinos: cavalo, } \\
\text { jegue. }\end{array} \\
\end{array}$ & $\begin{array}{l}\text { Sapo, cobra, } \\
\text { nico. }\end{array}$ & & & \\
\hline $\begin{array}{l}\text { Anfíbios: sapo, } \\
\text { tatu. }\end{array}$ & $\begin{array}{l}\text { Insetos: formiga, } \\
\text { mosca, aranha. }\end{array}$ & \multirow{4}{*}{$\begin{array}{l}\text { Jacaré, teiú, } \\
\text { camaleão, } \\
\text { tatu. }\end{array}$} & $\begin{array}{l}\text { Camaleão, teiú, } \\
\text { cobra, sapo. }\end{array}$ & Tatu, saruê. & $\begin{array}{l}\text { Saruê, coelho, } \\
\text { porco, cutia, } \\
\text { mocó. }\end{array}$ \\
\hline $\begin{array}{l}\text { Frutos do mar: } \\
\text { bacalhau, camarão. }\end{array}$ & \multirow{3}{*}{$\begin{array}{l}\text { Outros: nico, } \\
\text { macaco, camelo, } \\
\text { canguru, elefante, } \\
\text { girafa. }\end{array}$} & & \multirow{3}{*}{$\begin{array}{l}\text { Canguru, } \\
\text { camelo. }\end{array}$} & \multirow{3}{*}{$\begin{array}{l}\text { Carneiro, cabra, } \\
\text { boi, cavalo, } \\
\text { jegue, porco. }\end{array}$} & $\begin{array}{l}\text { Domésticos: } \\
\text { gato, cachorro. }\end{array}$ \\
\hline $\begin{array}{l}\text { Repteis: Camaleão, } \\
\text { jacaré, cobra, } \\
\text { crocodilo, teiú, } \\
\text { cutia. }\end{array}$ & & & & & $\begin{array}{l}\text { Velozes: onça, } \\
\text { leopardo, } \\
\text { guepardo. }\end{array}$ \\
\hline $\begin{array}{l}\text { Aracnídeos: } \\
\text { aranha. }\end{array}$ & & & & & $\begin{array}{l}\text { Vivem na água: } \\
\text { sapo. }\end{array}$ \\
\hline
\end{tabular}

Figura 5. Classificações feitas pelos grupos de estudantes do $7^{\circ}$ ano 
Na classificação feita pelo grupo E, destaca-se a categoria "animais da caatinga" que inclui mocó, cutia, saruê, coelho, tatu e sapo. Conforme discutido anteriormente, muitos dos animais foram classificados dessa forma por pertencer ao convívio dos estudantes, tornando-se representativos desse bioma. O grupo classificou os demais animais em "suínos", "bovinos", "equinos" e "caprinos", termos próprios de atividades agropecuárias que visam a criação de animais para fins econômicos e de consumo. Os estudantes estão familiarizados com tais termos, uma vez que na escola eles diariamente estão envolvidos em atividades relacionadas à suinocultura, caprinocultura, entre outras, aprendendo sobre criação e manejo desses animais.

Uma classificação um tanto diferenciada foi feita pelo grupo F. Os animais foram classificados pela visão que os alunos têm sobre as relações mantidas entre eles. A justificativa para tal classificação foi a seguinte:

Nós separamos os animais que se dão bem. Por exemplo, esse daqui, teiú só anda rastejando como o jacaré, camaleão, são quase da mesma raça. Alguns a gente separou por espécie, o gato e o cachorro a gente colocou junto por que alguns se dão bem, tem gato e cachorro que só vivem brigando. Se parecem e se dão bem, vivem no mesmo lugar. O grupo que tem o sapo, a cobra, e o nico são nojentos, feios, esse aqui não, esse aqui é fofinho (falando do nico) a cobra tem raiva do sapo.

Os seres vivos mantêm diversos tipos de relações entre si, por exemplo, sociedade, mutualismo, comensalismo etc. Com "se dar bem" o grupo tentou dizer que existe algum tipo de relação harmônica entre os animais que foram colocados juntos, como o gato e o cachorro que foram agrupados juntos, mas em alguns casos o "se dar bem" parece expressar modo de vida, mesmo habitat e semelhança morfológica, pois eles falam que alguns animais se parecem. As semelhanças morfológica, comportamental e ecológica foram critérios utilizados por muitos grupos para classificar os animais, por exemplo como citado pelo grupo D: "Eles são da mesma família e são bastante parecidos. É a questão de ter pelos, a aparência e também você vê que o formato".

Em trabalho realizado por Oliveira et al. (2011), utilizando a metodologia de classificações intuitivas, resultado semelhante foi observado. Os autores apontam que uma das explicações para tal é que nas escolas prevalece um ensino de ciências descritivo. Costa e Waizbort (2013) também realizaram atividade similar com estudantes de ensino médio, intitulada de "classificação espontânea", em que também se evidenciou que, ao classificar os animais, os estudantes utilizavam características que, de alguma forma, os aproximavam, revelando um pensamento essencialista.

Este pensamento, segundo Amorim (2008), tem origem em Aristóteles, para o qual as semelhanças entre as espécies teriam origem em essências compartilhadas e os seres seriam então classificados com base nessas características/essências compartilhadas. Isto poderia explicar o porquê da busca por características semelhantes como critério utilizado pelos participantes dessa pesquisa, como perceptível nas falas: "a gente utilizou as características tipo assim deles terem como se fossem escamas" (falando dos répteis) ou ainda "Eles são da mesma família e são bastante parecidos. É a questão de ter pelos" 
(falando sobre felinos, como se ter pelos, mamas, escamas constituíssem a essência desses animais).

A partir dessa proposta foi possível conhecer diferentes categorias diretamente associadas à percepção dos estudantes sobre a fauna, muitas das quais não apresentam valor taxonômico, mas são significativas por expressarem o valor simbólico e cultural que os estudantes da EFA atribuem aos animais que pertencem ou não ao seu ambiente e convívio. Sobre o conhecimento apresentado pelos estudantes, além de ser justificado pelo histórico ensino ministrado nas escolas, é notório que este tem forte relação com o contexto em que eles se inserem. As informações levantadas nessa etapa foram utilizadas na finalização dessa proposta em que se buscou promover o diálogo entre o saber tradicional e o científico, conforme apresentado no próximo tópico.

\section{Diálogo de saberes: conversando sobre as classificações}

No último encontro, buscamos estabelecer o diálogo entre as classificações intuitivas, feitas pelos estudantes e a classificação feita a partir dos critérios estabelecidos pela sistemática filogenética, representando o conhecimento científico. Para tanto, resgatamos todos os materiais produzidos nas etapas anteriores, os desenhos e os cartazes com as classificações, organizando-os em forma de livreto (Sousa, \& Silva, 2017). Este livreto contém uma apresentação inicial, narrando sobre o processo da oficina com os estudantes, bem como descrições de todos os animais citados por eles nas oficinas, com notas explicativas sobre suas características morfológicas e hábitos, acompanhadas de imagens ilustrativas retiradas da internet e desenhos produzidos pelos estudantes. Além dessas descrições dos animais, podem ser encontradas no livreto digitalizações de cartazes produzidos pelos estudantes apresentando suas classificações intuitivas, bem como um cartaz que produzimos com base na classificação filogenética, acompanhado de um cladograma, demonstrando as relações de parentesco entre os animais citados na oficina.

Nesse cartaz, os animais foram organizados em grandes grupos conforme os parâmetros da sistemática, para demonstrar aos estudantes que diferentes espécies podem ser reunidas em determinado grupo quando utilizamos outros critérios além dos morfológicos, como dados moleculares, embriológicos, fisiológicos, comportamentais, entre outros, estabelecendo relações de parentesco entre as espécies. Os grupos formados foram: Arthropoda, Vertebrata, Tetrapoda, Archossauria, Mammalia, Carnivora, todos esses grupos compartilham características e possuem um ancestral comum, configurando o que na sistemática é chamado de grupo monofilético, único reconhecido como grupo válido.

Essa abordagem zoológica, por meio da sistemática filogenética, é uma ferramenta que possibilita a compreensão de como os animais estão historicamente conectados, bastante referenciada para o nível médio (Ferreira et al., 2008; Rodrigues, Justina, \& Meglhioratti, 2011), passível de ser utilizada também nas aulas de Ciências, por permitir a integração de diversos conceitos biológicos e por tornar o processo de aprendizagem 
mais dinâmico, observando as especificidades de cada nível educacional.

Desse modo, o livreto pode ser utilizado pelos estudantes e professores da EFA como material didático, por abordar uma compreensão sobre diferentes modelos utilizados para classificar os seres vivos, incluindo modelos intuitivos, além da sistemática filogenética, exemplificando as relações de parentesco entre diversos animais conhecidos pelos estudantes.

É importante frisar que essa atividade não tinha o intuito de fazer com que os estudantes abandonassem o conhecimento construído e aprendido sobre animais, mas sim apresentar uma forma diferente de classificar esses animais, aproximando-os da linguagem científica, apresentando esse conhecimento como uma segunda cultura, "que tem seus próprios domínios de validade e compromissos filosóficos, sobre a qual poderão perceber a existência de relações de semelhanças e/ou diferenças" (Baptista, 2010, p. 690).

A primeira questão que os alunos notaram se relacionou às semelhanças entre a classificação feita com base no conhecimento científico e as classificações intuitivas. Alguns fizeram comentários do tipo "eu fiz certo" quando percebiam essas semelhanças. Esse momento foi oportuno para comentar que não havia algo certo ou errado, já que eles notaram também algumas diferenças, porque nos dois casos foram usados critérios diferentes para agrupar os animais. Conforme Baptista (2010), as diferentes visões de natureza que os estudantes possuem podem ou não ser compatíveis com a visão científica. Assim o diálogo entre essas visões não visa a hierarquização do conhecimento, mas sim uma oportunidade para que ideias distintas sejam expostas e consideradas, respeitando o alcance e aplicação de cada uma.

Ainda utilizando os cartazes, foi chamada a atenção dos estudantes para o grupo que continha a aranha, formiga, mosca e o camarão - os Artrópodes. Logo alguns se lembraram dos "insetos", um dos estudantes disse que nem todos são insetos, que aranha não é inseto (o mesmo que na etapa anterior classificou a aranha como aracnídeo), mas que "eles têm alguma característica em comum". Então reforçamos que a aranha e o camarão não são insetos, mas podem ser reunidos em um grupo chamado Artrópodes, que são animais que possuem pernas articuladas e esqueleto externo - que logo eles identificaram como exoesqueleto. Aproveitamos para dizer que o grupo artrópodes pode ser subdividido em grupos menores, e citamos os representados entre os animais escolhidos, como os insetos (mosca e formiga), aracnídeos (aranha) e crustáceos (camarão).

Refletindo sobre o trecho acima é possível concluir que conteúdos específicos da sistemática filogenética podem ser trabalhados no ensino fundamental sem tornar o assunto cansativo. Atentando para o nível educacional dos estudantes, optou-se por uma dinâmica de conversa sem fazer uso de termos que são difíceis de ser compreendidos, até mesmo no ensino superior. O objetivo não era fazê-los decorar terminologia, mas promover por meio do diálogo o entendimento do significado de conceitos como, por exemplo, sinapomorfia, plesiomorfia, grupo monofilético, parafilético, fornecendo 
assim uma base para futura ampliação dos conhecimentos. Tal reflexão se respalda no pensamento de Rocha, Duso e Maestrelli (2013) sobre o ensino de Ciências amparado na perspectiva da sistemática filogenética, a qual permite a elucidação dos conceitos zoológicos sem, contudo, conferir um espaço privilegiado no ensino à memorização de um excesso de termos.

Os estudantes apontaram na classificação científica um grupo que lhes chamou atenção, pois eles ficaram surpresos com o fato de que aves, jacaré e crocodilo pertenciam a um mesmo grupo chamado Archosauria. Para classificar os animais, eles usaram como critérios basicamente a aparência e habitat. Assim, em nenhuma das classificações intuitivas aves e répteis apareceram juntos, pois para eles são animais morfologicamente distintos com modos de vida distintos. Surgiram comentários como: "por quê?"; "E jacaré tem asa?”. Essa foi uma oportunidade de enfatizar que, na classificação científica, são considerados outros aspectos além da anatomia, como o desenvolvimento e a história evolutiva. No caso de aves e crocodilianos, discutimos com os estudantes que esses animais partilham um ancestral comum, por isso podem ser reunidos em um grande grupo, o Archosauria.

\section{Conclusões}

Sobre a biodiversidade, Orozco (2017, p. 175) nos diz que seu conceito é "integrador e polissêmico", pois compreende diferentes significados quando abordado por diferentes perspectivas. Esse aspecto propõe desafios e questionamentos sobre o ensino da biodiversidade, principalmente quanto a abordá-la para além de seus aspectos biológicos, ecológicos e evolutivos. Nessa proposta, além do estudo taxonômico, o qual consideramos importante, por permitir a ampliação do sentido biológico do termo, foi possível viabilizar um espaço para trabalhar o sentido cultural da diversidade animal conhecida pelos estudantes.

Essa pesquisa evidenciou aspectos próprios da cultura local e também o saber dos estudantes, fruto das interações estabelecidas com o meio onde vivem. Entendemos que, ensinar ciências em uma perspectiva multicultural é sempre um desafio a ser superado, tendo em vista a multiplicidade de culturas presentes na sala de aula e todas as limitações impostas pelo contexto educacional em que se insere a educação brasileira. Nossos resultados vão ao encontro do que defendem Cardoso e Araújo (2011), quando afirmam que as escolas do campo devem construir um currículo que responda aos anseios dos camponeses, e sensível à cultura local. $\mathrm{O}$ professor pode sempre em sua prática buscar estratégias que permitam a exposição e a valorização do conhecimento que o estudante traz consigo para a escola.

Nessa perspectiva, o uso de classificações intuitivas no ensino de ciências se mostrou produtivo, porque quando se abre espaço para que o estudante exponha suas ideias e visões de mundo, torna-se possível utilizar esse conhecimento para, a partir dele, trabalhar conceitos científicos, de forma que o saber do estudante seja considerado e valorizado. Desse modo, tornou-se possível uma contextualização do ensino de ciências, 
na medida em que, recorrendo aos conhecimentos populares, valoriza-se a cultura e os sistemas de conhecimento diferentes do conhecimento científico, tal como sugerem Andrade et al. (2014), ao investigar as classificações intuitivas de estudantes indígenas.

Percebemos que há um vasto horizonte de possibilidades, sobretudo no campo de aplicação da etnobiologia, no que concerne à cooperação entre o saber tradicional e o conhecimento científico, visando a conservação de saberes especificamente os produzidos no âmbito das comunidades tradicionais. Tal proposição encontra respaldo em Posey (1986) principalmente no que diz respeito à possiblidade de entender o que os diferentes grupos sociais compreendem sobre questões biológicas. Os estudos e abordagens de cunho etnobiológico permitem entender como se dá a construção das relações estabelecidas com animais considerando os aspectos culturais de cada grupo social, podendo contribuir para que as sociedades mantenham relações com a natureza que visem a preservação de seus constituintes, bem como a preservação dos saberes produzidos e aprendidos a partir da relação direta que o ser humano mantém com o meio que o circunda.

Por fim, a abordagem utilizada na presente pesquisa, o estudo da biodiversidade animal por meio da articulação entre classificação intuitiva e a sistemática filogenética, mostra grande potencial enquanto estratégia que permite a criação de um espaço em que os estudantes possam interagir e participar, promovendo o diálogo entre professor/ aluno/conteúdo.

Esperamos que a troca de saberes, aqui proposta, possa contribuir com as pesquisas na área, tanto teoricamente, para a afirmação da legitimidade do conhecimento tradicional, quanto metodologicamente, para a contextualização do ensino de ciências, em especial, no contexto educacional do campo.

\section{Agradecimentos}

Agradecemos a toda equipe pedagógica da Escola Família Agrícola Avani de Lima Cunha, no município de Valente (BA), pela parceira nesta pesquisa-intervenção. Agradecemos também ao MEC, pelo financiamento à pesquisa, por meio do edital PROEXT/MEC 2013.

\section{Referências}

Alves, R. R. N., Mendonça, L. E. T., Confessor, M. V. A., Vieira, W. L. S., \& Lopez, L. C. S. (2009). Hunting strategies used in the semi-arid region of northeastern Brazil. Journal of Ethnobiology and Ethnomedicine, 5(12), 5-12. Recuperado de https://ethnobiomed. biomedcentral.com/articles/10.1186/1746-4269-5-12.

Amorim, D. S. (2008). Paradigmas pré-evolucionistas, espécies ancestrais e o ensino de zoologia e botânica. Ciência \& Ambiente, 19(36), 125-150. 
Andrade, R. C., Tavares, M. de L., Dumont, E., Silveira Júnior, C. da., \& Valadares, J. M. (2014). Classificação biológica: uma experiência pedagógica junto a estudantes de um curso de formação intercultural de educadores indígenas. Revista da SBEnBio. 7, 63926402. Recuperado de https://docplayer.com.br/28672877-Classificacao-biologica-umaexperiencia-pedagogica-junto-a-estudantes-de-um-curso-de-formacao-interculturalde-educadores-indigenas.html.

Baptista. G. C. S. (2010). Importância da demarcação de saberes no ensino de ciências para sociedades tradicionais. Ciência \& Educação, 16(3), 679-694. Recuperado de http:// www.scielo.br/pdf/ciedu/v16n3/v16n3a12.pdf.

Bardin, L. (2004). Análise de conteúdo. Edições 70.

Constituição da República Federativa do Brasil de 1988. Recuperado de http://www. planalto.gov.br/ccivil_03/Constituicao/Constituicao.htm.

Cardoso, L. R., \& Araújo, M. I. O. (2012). Currículo de ciências: professores e escolas do campo. Ensaio, 14(2), 121-135, Recuperado de http://www.scielo.br/pdf/epec/ v14n2/1983-2117-epec-14-02-00121.pdf.

Costa, R. G. A. (2008). Os saberes populares da etnociência no ensino das ciências naturais: uma proposta didática para aprendizagem significativa. Revista Didática Sistêmica, 8, 162-172. Recuperado de https://periodicos.furg.br/redsis/article/view/1303.

Costa, L. de O., \& Waizbort, R. F. (2013). Concepções de alunos do ensino médio sobre o tema classificação biológica. Revista Investigações em Ensino de Ciências, 18(3), 667-680. Recuperado de: https://www.if.ufrgs.br/cref/ojs/index.php/ienci/article/view/119/83.

Costa Neto, E. M. (2000). The significance of the category 'insect' for folk biological classification systems. Journal of Ecological Anthropology, 4, 70-75. Recuperado de http://scholarcommons.usf.edu/cgi/viewcontent.cgi?article=1090\&context=jea.

Costa Neto, E. M., \& Pacheco, J. M. (2004). A construção do domínio etnozoológico "inseto" pelos moradores do povoado de Pedra Branca, Santa Terezinha, Estado da Bahia. Acta Scientiarum. Biological Sciences, 26(1), 81-90.

Diegues, A. C. S. (2000). Etnoconservação: novos rumos para a conservação da natureza. São Paulo: Hucitec-NUPAUB-USP.

Dunker, C. I. L. (2016). Teoria Psicanalítica do Amor pelos Animais. Diversitas, 4(5), 161-178. Recuperado de https://docplayer.com.br/31784262-Neste-artigo-examinoteoria-psicanalitica-do-amor-pelos-animais-amorosa-entre-humanos-e-animais.html

Ferreira, F. S., Brito, S. V., Ribeiro, S. C., Sales, D. L., \& Almeida, W. de O. (2008). A zoologia e a botânica do ensino médio sob uma perspectiva evolutiva: uma alternativa de ensino para o estudo da biodiversidade. Cadernos de Cultura e Ciência, 2(1), 58-66. Recuperado de http://periodicos.urca.br/ojs/index.php/cadernos/article/download/19/19-59-2-PB. 
Freire, P. (1992). Pedagogia da Esperança: um reencontro com a pedagogia do oprimido. Paz e Terra.

Freixo, A. A. (2010). Do Sertão dos Tocós ao Território do Sisal: rumo à invenção de uma região e uma vocação. Geografares, (8), 1-23. Recuperado de https://periodicos. ufes.br/geografares/article/view/1287.

Gimonet, J. (2007). Praticar e compreender a Pedagogia da Alternância dos CEFFAs. Vozes.

Lima, E. de S. (2011). Currículo das escolas do campo: perspectivas de rupturas e inovação. In E. de S. Lima \& A. M. da Silva (Orgs.), Diálogos sobre Educação do Campo. EDUFPI.

Mayr, E. (1998). O desenvolvimento do pensamento biológico: diversidade, evolução e herança. UNB.

Novais, E. S. P., Fonseca, K. N., Freitas, A. C. S., \& Milli, J. C. (2016). Contribuições dos pressupostos freireanos para a organização curricular de ciências na educação do campo. Revista da SBEnBio, 9, 6040-6051.

Oliveira, D. B. G., Boccardo, L., Souza, M. L., Luz, C. F. da S., Souza, A. L. S., Bitencourt, I. M., \& Santos, M. C. dos. (2011). O Ensino de Zoologia numa perspectiva evolutiva: análise de uma ação educativa desenvolvida com uma turma do Ensino Fundamental. In VIII Encontro Nacional de Pesquisa em Educação em Ciências (p. 1-12), Campinas, São Paulo: ABRAPEC. Recuperado de: http://www.nutes.ufrj.br/abrapec/viiienpec/ resumos/R0083-1.pdf.

Oliveira, L. S., \& Souza, M. L. (2014). Articulando o ensino de zoologia com a etnozoologia: análise de uma proposta educativa com estudantes do ensino fundamental. Revista da SBEnBio, 7, 5470-5481. Recuperado de http://docplayer.com.br/16249059-Articulandoo-ensino-de-zoologia-com-a-etnozoologia-analise-de-uma-proposta-educativa-comestudantes-do-ensino-fundamental.html.

Orozco, Y. A. (2017). O ensino da biodiversidade: tendências e desafios nas experiências pedagógicas. Góndola, Enseñ Aprend Cienc., 12(2), 173-185. Recuperado de https:// revistas.udistrital.edu.co/index.php/GDLA/article/view/11599/pdf.

Pinto, L. C. L. (2011). Etnozoologia e conservação da biodiversidade em comunidades rurais da Serra do Ouro Branco, Minas Gerais (Dissertação de Mestrado em Ecologia de Biomas Tropicais). Universidade Federal de Ouro Preto, Ouro Preto, MG. Recuperado de http://www.repositorio.ufop.br/handle/123456789/2136.

Posey, D. A. (1986). Etnobiologia: teoria e prática. In D. Ribeiro, D. (Ed.), Suma etnológica brasileira. (pp. 15-25). Vozes. Recuperado de http://etnolinguistica.wdfiles.com/local-files/suma\%3Avol1p15-26/S1_0d_Introd_EtnobiologiaTeoriaEPratica_Posey.pdf 
Rocha, A. L. F., Duso, L., \& Maestrelli, S. R. P. (2013) Contribuições da Filogenética para um ensino crítico da Zoologia. Anais do Encontro Nacional de Pesquisa em Educação em Ciências, Águas de Lindóia, SP, Brasil, 9. Recuperado de http://www.nutes.ufrj.br/ abrapec/ixenpec/atas/resumos/R0299-1.pdf.

Rodrigues, M. E., Justina, L. A. D., \& Meglhioratti, F. A. (2011). O Conteúdo de sistemática e filogenética em livros didáticos do ensino médio. Ensaio, 13(2), 65-84. Recuperado de https://seer.ufmg.br/index.php/ensaio/article/view/8567.

Roma, V. N., \& Motokane, M. T. (2007). Classificação biológica nos livros didáticos de Biologia do ensino Médio. Anais do Encontro Nacional de Pesquisa em Educação em Ciências, Florianópolis, SC, Brasil, 6. Recuperado de http://www.nutes.ufrj.br/abrapec/ vienpec/CR2/p878.pdf.

Santos-Fita, D., \& Costa Neto, E. M. (2007). As interações entre os seres humanos e os animais: a contribuição da etnozoologia. Biotemas, 20(4), 99-110. Recuperado de https://periodicos.ufsc.br/index.php/biotemas/article/view/20624/18800.

Silva, M. S. (2006). Da raiz à flor: produção pedagógica dos movimentos sociais e a escola do campo. In M. C. Molina (Org.) Educação do Campo e Pesquisa: questões para reflexão (pp. 60-93). Ministério do Desenvolvimento Agrário. Recuperado de: http:// www.gepec.ufscar.br/publicacoes/livros-e-colecoes/livros-diversos/educacao-docampo-e-pesquisa-questoes-para.pdf/view.

Silva, H. L. (2008). Educação do Campo e Pedagogia da Alternância: a experiência brasileira. Revista de Ciências da Educação, 5, 105-112.

Silva, M. R. A. (2016). Uso de animais em uma comunidade rural do semiárido brasileiro: um enfoque etnozoológico. (Dissertação de Mestrado em Ecologia e Conservação). Universidade Estadual da Paraíba, Campina Grande, PB. Recuperado de http://tede. bc.uepb.edu.br/jspui/handle/tede/2466.

Sousa, D. K. C. de, \& Silva, I. T. da. (2017). Bichos e plantas que conhecemos! Trabalhando biodiversidade e classificação. Recuperado de https://www.researchgate.net/ publication/333224444_Bichos_e_plantas_que_conhecemos.

Trindade, O. S. N., Silva Júnior, J. C., \& Teixeira, P. M. M. (2012). Um estudo das representações sociais de estudantes do ensino médio sobre os insetos. Revista Ensaio, 14(3), 37-50. Recuperado de http://www.scielo.br/pdf/epec/v14n3/1983-2117epec-14-03-00037.pdf.

Tripp, D. (2005). Pesquisa-ação: uma introdução metodológica. Educação e Pesquisa, 31(3), 443-466. Recuperado de: http://www.scielo.br/pdf/\%0D/ep/v31n3/a09v31n3. pdf. 
Torres, R., Rodrigues, G. R., \& Barreto, R. M. F. (2015). Etnozoologia como ferramenta na educação ambiental- os saberes populares como informação valiosa para a conservação: vivências na floresta nacional de negreiros, Serrita-PE. Extramuros - Revista de Extensão da Univasf, 3(1), 191-200. Recuperado de: http://periodicos2.univasf.edu.br/index.php/ extramuros/article/view/659/379.

Valle, Y. B. B. (2007). Vaqueiros do Sítio do Meio (Lagoa Grande-PE) e Mamíferos nativos da Caatingas Pernambucanas: percepções e interações. (Dissertação de Mestrado em Gestão e Políticas Ambientais). Universidade Federal de Pernambuco, Recife, PE. Recuperado de: https://repositorio.ufpe.br/handle/123456789/6371.

Waizbort, R. F. (2000). Cento e quarenta anos sem Darwin bastam: sobre espécies variedades e definições. Principia, 4(1), 141-184. Recuperado de https://periodicos. ufsc.br/index.php/principia/article/view/19478/17832.

Diany Kelly Cardoso de Sousa

http://orcid.org/0000-0003-1413-5232

Universidade Cruzeiro do Sul

Brasília, Distrito Federal, Brasil dianisousa@hotmail.com

Alessandra Alexandre Freixo

http://orcid.org/0000-0003-3566-8302 Universidade Estadual de Feira de Santana

Departamento de Educação Feira de Santana, Bahia, Brasil aafreixo@uefs.br

Submetido em 15 de novembro de 2019

Aceito em 18 de março de 2020

Publicado em 07 de abril de 2020 